\title{
Development of Nomograph Chart for Pervious Concrete Containing Coated Biomass Aggregate
}

\author{
Salaheddin Arafa ${ }^{1}$, Ahmed Elmesh ${ }^{2}$, Otman M. M. Elbasir ${ }^{3}$, Nur Izzi Md. Yusoff ${ }^{4}$, \\ Abdalrhman Milad ${ }^{4, *}$

\begin{abstract}
${ }^{1}$ Faculty of Civil Engineering and Built Environment, University Tun Hussein Onn Malaysia, Parit Raja 86400, Johor, Malaysia ${ }^{2}$ High Institute of Comprehensive Professions, Civil Engineering, Tripoli, Libya

${ }^{3}$ High Institute of Science and Technology, Civil Engineering, Qaser Bin Gashear, Libya

${ }^{4}$ Department of Civil Engineering, Universiti Kebangsaan Malaysia (The National University of Malaysia), UKM Bangi 43600, Selangor, Malaysia
\end{abstract}

Received February 8, 2021; Revised July 26, 2021; Accepted August 9, 2021

\section{Cite This Paper in the following Citation Styles}

(a): [1] Salaheddin Arafa, Ahmed Elmesh, Otman M. M. Elbasir, Nur Izzi Md. Yusoff, Abdalrhman Milad, "Development of Nomograph Chart for Pervious Concrete Containing Coated Biomass Aggregate," Civil Engineering and Architecture, Vol. 9, No. 5A, pp. 47 - 57, 2021. DOI: 10.13189/cea.2021.091306.

(b): Salaheddin Arafa, Ahmed Elmesh, Otman M. M. Elbasir, Nur Izzi Md. Yusoff, Abdalrhman Milad (2021). Development of Nomograph Chart for Pervious Concrete Containing Coated Biomass Aggregate. Civil Engineering and Architecture, 9(5A), 47 - 57. DOI: 10.13189/cea.2021.091306.

Copyright $\odot 2021$ by authors, all rights reserved. Authors agree that this article remains permanently open access under the terms of the Creative Commons Attribution License 4.0 International License

\begin{abstract}
Pervious concrete is an effective and unique way to overcome critical environmental issues and support green, sustainable growth. Pervious concrete refers to a non-slip porous pavement concrete, which is permeable to water. Recently, the demand for sustainable waste palm oil products for construction in Malaysia has dramatically increased. For long-term sustainable development, palm products waste can be recycled in pervious concrete production. This study on pervious geopolymer concrete (hereafter PGC) explored an alternative binder and aggregate for Portland cement (OPC) and natural aggregate (NA), while it also developed a pervious concrete's compressive strength. Biomass aggregate (BA) was obtained by burning palm oil biomass. Thus, biomass aggregate (BA) is introduced as a replacement for natural aggregate (NA). In order to generate coated biomass aggregates (CBA), BA was combined with alkaline liquid (AL) and fly ash (FA) and then heated inside an oven at 80 degrees Celsius for 24 hours. PGC containing coated biomass aggregate is the most commonly used cement substitute in concrete as the industrial by-product waste. This study investigated the performance and optimised mixture design of various PGC mixtures that incorporated NA to replace BA CBA compared with OPC pervious concrete containing NA. PGC generated via CBA possessed greater compressive strength without any impact
\end{abstract}

on permeability to water. Outcomes show that both CBA and BA are possible alternative aggregates for generating PGCs. As a result of this study, a nomograph chart was developed, which provided a guideline for designing PGC made by $\mathrm{CBA}$ and $\mathrm{BA}$, and cement pervious concrete made with NA.

Keywords Pervious Concrete, Green Sustainable, Geopolymer, PGC, CBA, Nomograph Chart

\section{Introduction}

In the management of storm-water runoff at a local and regional level, pervious concrete is one of the ideal methods recommended by the global community of civil engineers [1-2]. The aim behind its generation was for it to serve as permeable pavement, thermal insulation, eco-friendly material for acoustic absorption, water purification, and other architecture, and to be used in civil engineering applications [2-3]. Usually, the hardened concretes observe between $15-25 \%$ voids. Water's flow rate through pervious concrete is usually approximately $480 \mathrm{in} . / \mathrm{hr}\left(0.34 \mathrm{~cm} / \mathrm{s}, 200 \mathrm{~L} / \mathrm{m}^{2} / \mathrm{min}\right.$ or 5.0 gals $\left./ \mathrm{ft}^{2} / \mathrm{min}\right)$, even though the figures can be higher than that [4]. 
Moreover, pervious concrete consists of Portland cement with lower compressive strength than regular concrete $[5,6]$. However, cement manufacturing is essentially an energy-consuming process and tends to release high levels of greenhouse gases into the atmosphere. In order to lower Portland cement and enhance the pervious concrete's strength, there is a need to build supplementary materials to partially substitute Portland cement and act as a substitute cementing material. A geopolymer binder is a possible alternative cement generated via mixing high alkaline solutions with aluminosilicate material [7-9].

One of the biggest exporters and producers of palm oil products in the world is Malaysia. Waste by-products are produced at all stages of palm oil processing. Palm oil clinker is one of such by-products; it is obtained from oil palm shells and the combustion of palm fibre. Husks and fibres serve as fuel to raise the boiler to high temperatures in the steam engine utilised to extract oil [10]. Such a process generates palm oil clinkers in large volumes that range in sizes from 100-400 mm. Based on intended sizes, the clinkers are broken down into smaller particles termed biomass aggregates (BAs). As a substitute for normal coarse aggregates (CAs) in construction manufacturing, the BA lowers environmental pollution and acts as an alternative to the NA's lessening source [11].

Compared to traditional aggregates, the BAs possess poor impact and crushing values, excessive absorption of water, great porosity, and poor texture of surface [1]. Researchers have attempted to enhance recycled products such as concrete, which utilise agriculture waste as a component. Different strategies have been implemented to pinpoint the form of an aggregate coating that would enhance the strength of concrete. However, the coating of BAs with a geopolymer paste was suggested to enhance a coarse aggregate within concrete [2]. A thin geopolymer paste is used to coat the BAs, which are then well-cured. In order to generate PGC, the coated biomass aggregate (CBA) is combined with an alkaline solution and fly ash. The aluminosilicate products of geopolymer, an inorganic polymer, are generated with alkaline liquid $[8,9]$. Geopolymer has excellent acidity and an excellent sulphate barrier; decent efficiency acres do not use concrete and decrease greenhouse gas emissions by up to $44 \%-64 \%$. In addition to excellent performance under high temperature, high early intensity geopolymer production, good resistance to sulphate and acid attacks, and high early strength, the special wastes such as fly ash and aggregates are also excellent sources of aluminosilicate [12,13]. Since geopolymers consist of by-products, they do not affect the environment as much as cement binders $[14,15]$.

Nomographs have prospered in various forms for almost 75 years, because they enable reliable and fast computations before the introduction of pocket calculators. Results from a nomograph can be acquired very rapidly and accurately by merely drawing one or more lines. Many nomographs include other beneficial markings, e.g. coloured regions and reference labels which provide users with valuable guideposts $[16,17]$. Moreover, nomographs are usually utilised in applications whereby the accuracy they offer is valuable and sufficient. Besides, a nomograph is utilised to counter-check answers obtained using other methods; the former is more exact but probably an error-prone calculation [18].

This research is based on the achievements reported by a few researchers worldwide and presents state-of-the-art ways in which to make PGC clearer and more understandable. This paper highlighted the experimental procedures used to investigate the performance of PGC incorporated with CBA as well as BA without NA compared with Portland cement pervious concrete containing NA. The experimental work includes the water permeability coefficient and compressive strength for hardened concrete.

A nomograph chart of pervious concretes was developed as a guideline for producing pervious cement concrete with NA and PGC with BA and CBA.

\section{Materials Used}

Based on the current research, the necessary materials for preparing cement pervious concrete specimens include Portland cement (OPC), natural aggregate (NA) as a coarse aggregate of $5-10 \mathrm{~mm}$, and water. The raw materials utilised in preparing PGC specimens include sodium silicate $\left(\mathrm{Na}_{2} \mathrm{SiO}_{3}\right)$ and sodium hydroxide $(\mathrm{NaOH})$ as alkaline activator, fly ash as a pozzolanic material, and two types of coarse aggregate (BA, CBA). In this investigation, all kinds of mixing proportions were tested. The use of X-ray fluorescence (XRF) in the chemical analysis of fly ash highlighted the presence of primary chemical compounds such as iron oxide $\left(\mathrm{Fe}_{2} \mathrm{O}_{3}\right)$, silicates $\left(\mathrm{SiO}_{2}\right)$, and aluminates $\left(\mathrm{Al}_{2} \mathrm{O}_{3}\right)$. Several other compounds in smaller percentages were also found. Fly ash particles are typically spherical and finer. As depicted in Table 1, the fly ash was obtained from Sejingkat Power Corporation in Sarawak, Malaysia

Table 1. Chemical composition of fly ash sample

\begin{tabular}{|c|c|}
\hline Elements & Fly Ashes Mukah, Sarawak Percentage (\%) \\
\hline $\mathrm{SiO}_{2}$ & 55.7 \\
\hline $\mathrm{Al}_{2} \mathrm{O}_{3}$ & 24.22 \\
\hline $\mathrm{Fe}_{2} \mathrm{O}_{3}$ & 9.1 \\
\hline $\mathrm{K}_{2} \mathrm{O}$ & 4.42 \\
\hline $\mathrm{CaO}$ & 2.45 \\
\hline $\mathrm{MgO}$ & 1.36 \\
\hline $\mathrm{TiO}_{2}$ & 1.34 \\
\hline $\mathrm{P}_{2} \mathrm{O}_{5}$ & 0.27 \\
\hline $\mathrm{BaO}$ & 0.25 \\
\hline $\mathrm{Na}_{2} \mathrm{O}$ & 0.21 \\
\hline $\mathrm{MnO}$ & 0.17 \\
\hline $\mathrm{C}$ & 0.11 \\
\hline
\end{tabular}


An alkaline solution was produced by combining sodium silicate with sodium hydroxide pellets of $98 \%$ purity. A local chemical supplier was sourced for the sodium pellets. The alkaline liquid was the sodium silicate solution $\left(\mathrm{SiO}_{2}=35.01 \%\right.$, water $=46.37 \%$ and $\mathrm{Na}_{2} \mathrm{O}=$ $16.84 \%$ by mass). Preparation of the sodium hydroxide liquid was carried out by dissolving sodium hydroxide pellets in tap water. Preparation of the alkaline solution needed to be done a minimum of a day before usage.

Two distinct coarse aggregates $(5-10 \mathrm{~mm})$ without any dust were utilised in the mixture of PGC in SSD condition (saturated surface dry): coated biomass aggregate (CBA) and biomass aggregate (BA). The pervious cement concentre was generated via natural stone aggregates under both saturated and dry surface conditions. The burning of palm oil biomass generated uncoated BA. In a furnace, palm oil kernel and palm oil fibre were incinerated at roughly 500 degrees Celsius. Such a process produces large chunks of palm oil clinkers that range from $100-400 \mathrm{~mm}$ in size. The clinkers are subsequently broken down into smaller pieces termed biomass aggregates (BAs). In order to enhance the BAs' performance as a coarse aggregate in concrete, coating of the BA with geopolymer paste was suggested. This coating process was carried out in a mixer in order to generate coated biomass aggregate (CBA). In terms of the activation of fly ash with $\mathrm{NaOH}$ solution (10 M concentration), based on Steenie and Rangan (2008), the solids must be dissolved in water to form a solution with a specific concentration [14]. Thus, the concentration of the sodium hydroxide solution could vary between $8 \mathrm{M}$ and $16 \mathrm{M}$. AL/FA $=0.5$ and sodium silicate $\mathrm{Na}_{2} \mathrm{SIO}_{3} / \mathrm{NaOH}=2.5$ led to generation of geopolymer paste. A coating of geopolymer paste with 1:7 FA/BA was placed on the BAs. The CBAs were stored inside at over 80 degrees Celsius for a duration of 24 hours. The three distinct forms of aggregates that are utilised in this research are shown in Figure 1.

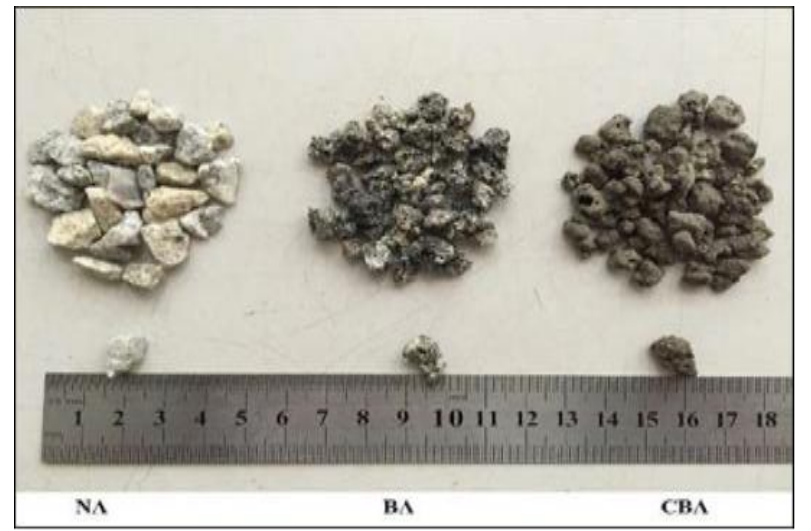

Figure 1. Various types of aggregate used

\section{Experimental Work}

\subsection{Portland Cement Pervious Concrete Mix}

The three selected parameters, which can be easily controlled, were percentage of cement paste (mass-based), water-to-cement ratio (w/c), and coarse aggregate size. The preparation of pervious concrete mixtures was categorised into three groups: M1, M2, and M3. The M1 mixtures were formulated to study the influence of cement content on the aggregate used in pervious concrete properties (OPC: NA). Moreover, the M2 mixtures were formulated to examine the effect of natural aggregate size on the properties of pervious concrete. The M3 mixtures were put together to examine the effect of the water-to-cement ratio (w/c) on the properties of pervious concrete. The best possible proportions of cement content were then acquired. Subsequently, the effect of other parameters was examined by formulating M2 and M3 mixtures, as shown in Table 2.

The best pervious concrete mixture was obtained by casting pervious concrete cubes to determine the size of the coarse aggregate, optimum cement content and water-to-cement ratio (w/c) based on compressive strength and water permeability. According to ACI (2010) and past studies, pervious concrete is made according to cement/coarse aggregate ratio by mass $(1: 3,1: 4,1: 5,1: 6$, and 1:7), size of coarse aggregate (5-10, 10-14, and 14-20 $\mathrm{mm})$, and the w/c ratio $(0.25,0.30,0.35$, and 0.4$)$. All samples were moulded into $100 \times 100 \times 100 \mathrm{~mm}$ cubes. The samples were kept at room temperature for 24 hours. After 24 hours of casting, the samples were subsequently disassembled and placed to cure immediately in $100 \%$ relative humidity in a water tank for 28 days.

\subsection{Pervious Geopolymer Concrete Containing BA and CBA Mix}

Pervious Portland cement concrete and PGC are different in terms of the binder used. The aluminium and silicon oxides in the low-calcium fly ash react with the alkaline liquid to produce the geopolymer paste, which can bind the loose coarse aggregates with other un-reacted substances to produce geopolymer concrete. The compressive strength and water permeability of PGC are affected by the properties and proportions of the component substances which produce the size of the coarse aggregate, fly ash-to-coarse aggregate ratio and geopolymer paste.

The optimum PGC mixture was obtained by casting PGC cubes to acquire the optimum ratios of AL/FA, FA-to-CBA content (FA: CBA), and size of CBA sodium hydroxide concentration (molarity) based on compressive strength and water permeability. The preparation of PGC mixtures was categorised into certain groups, namely M1, M2, M3, and M4. First, the M1 mixtures were developed to determine the effect of FA: CBA on the properties of PGC. Second, the M2 mixtures were developed to examine the effect of the size of CBA on the properties of PGC. Thirdly, the M3 mixtures were cultivated to 
examine the effect of the alkaline liquid-to-fly ash (AL/FA) ratio on the properties of PGC.

In contrast, the M4 mixtures were formulated to examine the effect of the sodium hydroxide solution concentration on the properties of PGC properties. Therefore, an optimum proportion of aggregate content can be acquired. Hence, the effect of other parameters was determined by formulating the M2, M3, and M4 mixtures, as shown in Table 3.

PGC was formed with FA: CBA ratios (1:6, 1:7, 1:8, and 1:9), the sizes of the CBAs (5-10 mm, 10-14 mm, and $14-20 \mathrm{~mm}), \mathrm{AL} / \mathrm{FA}$ ratios $(0.4,0.5$, and 0.6$)$, and the $\mathrm{NaOH}$ concentrations $(8,10$, and $12 \mathrm{M})$. The $\mathrm{Na}_{2} \mathrm{SIO}_{3} / \mathrm{NaOH}$ ratio was kept constant at 2.5 and cured at
80 degrees Celsius in an oven for 24 hours. The PGC mixture was created at 25 degrees Celsius in a controlled room. FA was blended with an alkaline liquid for 5 minutes in a pan-type mixer. In addition, the CBA was added and mixed for another minute. After mixing, the fresh PGC was moulded into $100 \mathrm{~mm}$ cubes and compacted via the usual method utilised for Portland cement concrete. The samples were wrapped with a thin plastic sheet to minimise loss of moisture before being treated at 80 degrees Celsius in an oven for 24 hours. The compressive strength and water permeability of the PGC were examined. All test trends corresponded to the well-known effect of various parameters and obtained the optimum mix for fly ash PGC containing CBA.

Table 2. Mixture design and number of specimens of OPC pervious concrete

\begin{tabular}{|c|c|c|c|c|c|c|c|}
\hline Specimen & $\begin{array}{c}\text { NA size } \\
(\mathbf{m m})\end{array}$ & W/C Ratio & OPC: NA & $\begin{array}{l}\text { Cement } \\
(\mathrm{kg} / \mathrm{m} 3)\end{array}$ & $\begin{array}{l}\text { Water } \\
\left(\mathrm{kg} / \mathrm{m}^{3}\right)\end{array}$ & $\mathbf{N A}\left(\mathbf{k g} / \mathbf{m}^{3}\right)$ & Remark \\
\hline C1-0.35/1:3 & $5-10$ & 0.35 & $1: 3$ & 550.64 & 165.19 & 1651.92 & \multirow{5}{*}{$\begin{array}{c}\text { Effect of } \\
\text { cement } \\
\text { content (M1) }\end{array}$} \\
\hline C2-0.35/1:4 & $5-10$ & 0.35 & $1: 4$ & 404.88 & 121.46 & 1619.52 & \\
\hline C3-0.35/1:5 & $5-10$ & 0.35 & $1: 5$ & 323.9 & 97.17 & 1619.5 & \\
\hline C4-0.35/1:6 & $5-10$ & 0.35 & $1: 6$ & 270.46 & 81.13 & 1622.76 & \\
\hline C5-0.35/1:7 & $5-10$ & 0.35 & $1: 7$ & 230 & 69 & 1610 & \\
\hline C6-0.35/1:4 & $5-10$ & 0.35 & $1: 4$ & 404.88 & 121.46 & 1619.52 & \multirow{3}{*}{$\begin{array}{c}\text { Effect of } \\
\text { aggregate size } \\
\text { (M2) }\end{array}$} \\
\hline C7-0.35/1:4 & $10-14$ & 0.35 & $1: 4$ & 404.88 & 121.46 & 1619.52 & \\
\hline C8-0.35/1:4 & $14-20$ & 0.35 & $1: 4$ & 404.88 & 121.46 & 1619.52 & \\
\hline C9-0.25/1:4 & $5-10$ & 0.25 & $1: 4$ & 404.88 & 121.46 & 1619.52 & \multirow{4}{*}{$\begin{array}{c}\text { Effect of (w/c) } \\
\text { (M3) }\end{array}$} \\
\hline C10-0.3/1:4 & $5-10$ & 0.3 & $1: 4$ & 404.88 & 141.7 & 1619.52 & \\
\hline C11-0.35/1:4 & $5-10$ & 0.35 & $1: 4$ & 404.88 & 161.95 & 1619.52 & \\
\hline C12-0.4/1:4 & $5-10$ & 0.4 & $1: 4$ & 404.88 & 182.19 & 1619.52 & \\
\hline
\end{tabular}

Table 3. Mixture design and number of specimens of PGC

\begin{tabular}{|c|c|c|c|c|c|c|c|c|}
\hline Specimen & $\begin{array}{c}\text { CBA } \\
\text { size }(\mathbf{m m})\end{array}$ & $\begin{array}{c}\mathbf{A L} / \mathbf{F A} \\
\text { ratio }\end{array}$ & $\begin{array}{l}\text { FA: } \\
\text { CBA }\end{array}$ & $\begin{array}{c}\mathrm{NaOH} \\
\text { molarity }\end{array}$ & $\begin{array}{l}\text { Fly ash } \\
\left(\mathrm{kg} / \mathrm{m}^{3}\right)\end{array}$ & $\begin{array}{c}\text { Alkaline } \\
\text { solution } \\
\left(\mathbf{k g} / \mathbf{m}^{3}\right)\end{array}$ & $\begin{array}{c}\text { CBA } \\
\left(\mathrm{kg} / \mathrm{m}^{3}\right)\end{array}$ & Remark \\
\hline $\mathrm{C} 1$ & $5-10$ & 0.5 & $1: 6$ & 10 & 226.67 & 113.34 & 1360 & \multirow{4}{*}{$\begin{array}{l}\text { Effect of FA: } \\
\text { CBA (M1) }\end{array}$} \\
\hline $\mathrm{C} 2$ & $5-10$ & 0.5 & $1: 7$ & 10 & 200 & 100 & 1400 & \\
\hline $\mathrm{C} 3$ & $5-10$ & 0.5 & $1: 8$ & 10 & 178.95 & 89.47 & 1431.57 & \\
\hline $\mathrm{C} 4$ & $5-10$ & 0.5 & $1: 9$ & 10 & 161.9 & 80.9 & 1457.14 & \\
\hline $\mathrm{C} 5$ & $5-10$ & 0.5 & $1: 7$ & 10 & 200 & 100 & 1400 & \multirow{3}{*}{$\begin{array}{l}\text { Effect of } \\
\text { aggregate size } \\
\text { (M2) }\end{array}$} \\
\hline C6 & $10-14$ & 0.5 & $1: 7$ & 10 & 200 & 100 & 1400 & \\
\hline $\mathrm{C} 7$ & $14-20$ & 0.5 & $1: 7$ & 10 & 200 & 100 & 1400 & \\
\hline $\mathrm{C} 8$ & $5-10$ & 0.4 & $1: 7$ & 10 & 202.38 & 80.95 & 1416.67 & \multirow{3}{*}{$\begin{array}{c}\text { Effect of AL/FA } \\
\text { (M3) }\end{array}$} \\
\hline $\mathrm{C} 9$ & $5-10$ & 0.5 & $1: 7$ & 10 & 200 & 100 & 1400 & \\
\hline $\mathrm{C} 10$ & $5-10$ & 0.6 & $1: 7$ & 10 & 197.67 & 118.6 & 1383.7 & \\
\hline $\mathrm{C} 11$ & $5-10$ & 0.5 & $1: 7$ & 8 & 200 & 100 & 1400 & \multirow{3}{*}{$\begin{array}{c}\text { Effect of } \\
\mathrm{NaOH} \\
\text { Molarity (M4) }\end{array}$} \\
\hline $\mathrm{C} 12$ & $5-10$ & 0.5 & $1: 7$ & 10 & 200 & 100 & 1400 & \\
\hline $\mathrm{C} 13$ & $5-10$ & 0.5 & $1: 7$ & 12 & 200 & 100 & 1400 & \\
\hline
\end{tabular}




\subsection{Compressive Strength}

In this study, all samples cast in $100 \mathrm{~mm}$ cubes were moulded, and tested after 24 hours using a $250 \mathrm{KN}$ capacity loading machine in displacement control at a rate of $1 \mathrm{~mm} / \mathrm{min}$ until failure. The mean value acquired from the five cubes was considered as the compressive strength for each PGC mixture.

\subsection{Water Permeability Test}

The permeability of PGC made with BA and CBA was compared with previous cement concrete with NA. Permeability is an essential parameter of previous concrete as it is created to be a drainage layer in pavement structures (please see Figure 2). The constant head method was utilised to examine PGC's water permeability coefficient conducted after a steady flow was achieved $[22,23]$. The coefficients of water permeability $(\mathrm{k})$ were the average of three specimens, which were calculated using Darcy's law, as displayed in Equation 1.

$$
K=(L \times Q)+A(L+H)
$$

where:

$$
\begin{aligned}
& \text { Q: the amount of water }\left(\mathrm{cm}^{3} / \mathrm{s}\right) \\
& \text { A: cross-section area of pavement }\left(\mathrm{cm}^{2}\right) \\
& \mathrm{H}:\left(\mathrm{h}_{1}-\mathrm{h}_{2}\right) \text { water level }(\mathrm{cm}) \\
& \mathrm{L}: \text { the thickness of pavement }(\mathrm{cm}) \\
& \mathrm{K} \text { : coefficient of water permeability }(\mathrm{cm} / \mathrm{s})
\end{aligned}
$$

\section{Nomograph Chart}

The nomograph chart, known as the nomograph for pervious concrete, was developed as a guideline for producing NA Portland cement pervious concrete, CBA and BA PGC. This guideline could help formulate pervious concrete with expected compressive strength values and water permeability. Three nomograph charts were adopted as follows.

First, the nomograph chart for NA Portland cement pervious concrete and CBA and BA PGC was compiled. This chart comprises the cement or fly ash-to-aggregate content, w/c ratio or $\mathrm{AL} / \mathrm{FA}$ ratio, compressive strength and water permeability as parameters.

Second is the nomograph chart for CBA and BA PGC. This chart comprises the $\mathrm{NaOH}$ molarity, AL/FA ratio, compressive strength and water permeability parameters.

Finally, the nomograph chart for CBA and BA PGC was formulated. This chart comprises the fly ash-to-aggregate content (FA: CBA) and FA: BA, $\mathrm{NaOH}$ molarity, compressive strength and water permeability as parameters. The details of the three nomograph charts are described in the results section.

\section{Results and Discussion}

\subsection{Pervious Cement Concrete}

The results of various pervious concrete mix specimens based on compressive strength and water permeability under different vital parameters are shown in Table 4.

\subsection{Pervious Geopolymer Concrete Containing BA and CBA}

The optimum CBA PGC mix was obtained by casting PGC cubes to determine the optimum ratio of FA/CBA, size of $\mathrm{CBA}$, the ratio of $\mathrm{AL} / \mathrm{FA}$, sodium hydroxide concentration (molarity) based on compressive strength and water permeability. PGC was created using FA/CBA (with ratios 1:6, 1:7, 1:8, and 1:9), CBA (with sizes of 5-10, 10-14, and 14-20 mm), AL/FA (with ratios of 0.4 , 0.5 , and 0.6$)$, and sodium hydroxide concentration $(8,10$, and $12 \mathrm{M}$ ). The $\mathrm{Na}_{2} \mathrm{SiO}_{3} / \mathrm{NaOH}$ ratio was kept constant at 2.5 and treated at 80 degrees Celsius in an oven for 24 hours. All test trends were analogous to the well-known effects of various parameters and obtained the optimum mix for fly ash PGC based on water permeability and compressive strength. The results of various CBA PGC mixture specimens based on water permeability and compressive strength under different key parameters are shown in Table 5.

\subsection{Establishment of Nomograph Chart for Pervious Concrete}

The nomograph chart developed in this study can be applied for producing concrete that uses NA Portland cement pervious concrete, CBA and BA PGC. Figure 2 shows the nomograph chart for NA Portland cement pervious concrete, CBA and BA PGC. However, this chart comprises cement or fly ash-to-aggregate content, w/c ratio or AL/FA ratio, compressive strength, and water permeability as parameters. Figure 3 presents the nomograph chart for CBA and BA PGC. This chart comprises the $\mathrm{NaOH}$ molarity, AL/FA ratio, compressive strength and water permeability parameters. The nomograph chart for CBA and BA PGC comprising fly ash-to-aggregate content (FA: CBA) and FA: $\mathrm{BA}, \mathrm{NaOH}$ molarity, compressive strength and water permeability as parameters. Figure 2 contains four quarters. The four quarters of these three curves indicate NA Portland cement pervious concrete, CBA PGC, and BA PGC. The first quarter relates to the cement-to-aggregate content (OPC: CA) and compressive strength of NA Portland cement pervious concrete mix, fly ash-to-aggregate content (FA: CBA and FA: BA) and compressive strength of $\mathrm{CBA}$ and $\mathrm{BA}$ PGC mix. In this quarter, the compressive strength of three different types of concrete can be determined by dragging the lines from the (OPC: 
CA) and (FA: CA) axis into the compressive strength axis.

In the second quarter, concrete compressive strength can be arbitrarily related to w/c of NA Portland pervious concrete or AL/FA of CBA and BA PGC. The w/c ratio for NA Portland cement pervious concrete and the AL/FA ratio for $\mathrm{CBA}$ and $\mathrm{BA}$ PGC can be identified from the compressive strength axis. The third quarter presents the w/c ratio for NA Portland cement pervious concrete and the AL/FA ratio for CBA and BA PGC related to water permeability of concrete. From the w/c and AL/FA ratio axis, the water permeability of concrete can be determined. The water permeability is in $\mathrm{cm} / \mathrm{sec}$ units. The fourth quarter relates to cement-to-aggregate content (OPC: CA) and water permeability of NA Portland cement pervious concrete mix, fly ash-to-aggregate content (FA: CBA), (FA: BA) and water permeability of CBA and BA PGC mix. From the (OPC: CA), (FA: CBA) and (FA: BA) axis, the water permeability of three different types of concrete can be determined.

The use of this nomograph chart can be viewed in the following sub-section.

Table 4. Results of compressive strength and water permeability for pervious concrete specimens with various parameters

\begin{tabular}{|c|c|c|c|c|c|c|}
\hline Specimen & $\begin{array}{l}\text { Aggregate } \\
\text { size }(\mathbf{m m})\end{array}$ & $\begin{array}{l}\text { W/C } \\
\text { Ratio }\end{array}$ & $\begin{array}{c}\text { Cement: } \\
\text { aggregate ratio }\end{array}$ & $\begin{array}{c}\text { Compressive } \\
\text { strength (MPa) }\end{array}$ & $\begin{array}{c}\text { Water } \\
\text { permeability } \\
(\mathrm{cm} / \mathrm{sec})\end{array}$ & Remark \\
\hline C1-1/0.3/1:3 & $5-10$ & 0.35 & $1: 3$ & 9.4 & 1.7 & \multirow{5}{*}{$\begin{array}{l}\text { Effect of } \\
\text { cement } \\
\text { content }\end{array}$} \\
\hline C2-1/0.3/1:4 & $5-10$ & 0.35 & $1: 4$ & 9.1 & 2 & \\
\hline C3-1/0.3/1:5 & $5-10$ & 0.35 & $1: 5$ & 8.5 & 2.05 & \\
\hline C4-1/0.3/1:6 & $5-10$ & 0.35 & $1: 6$ & 7.40 & 2.08 & \\
\hline C5-1/0.3/1:7 & $5-10$ & 0.35 & $1: 7$ & 6.20 & 2.13 & \\
\hline C6-1/0.3/1:4 & $5-10$ & 0.35 & $1: 4$ & 9.1 & 2 & \multirow{3}{*}{$\begin{array}{c}\text { Effect of } \\
\text { aggregate size }\end{array}$} \\
\hline C7-2/0.3/1:4 & $10-14$ & 0.35 & $1: 4$ & 6.4 & 2.1 & \\
\hline C8-3/0.3/1:4 & $14-20$ & 0.35 & $1: 4$ & 5.3 & 2.17 & \\
\hline C9-1/0.3/1:4 & $5-10$ & 0.25 & $1: 4$ & 6.2 & 2.15 & \multirow{4}{*}{ Effect of (w/c) } \\
\hline C101/0.35/1:4 & $5-10$ & 0.3 & $1: 4$ & 7.3 & 2.12 & \\
\hline C11-1/0.4/1:4 & $5-10$ & 0.35 & $1: 4$ & 9.1 & 2 & \\
\hline C12-1/0.45/1:4 & $5-10$ & 0.4 & $1: 4$ & 8.1 & 2.02 & \\
\hline
\end{tabular}

Table 5. Results of compressive strength and water permeability for CBA PGC specimens with various parameters

\begin{tabular}{|c|c|c|c|c|c|c|c|}
\hline Specimen & $\begin{array}{c}\text { CBA size } \\
(\mathbf{m m})\end{array}$ & $\begin{array}{c}\text { AL/FA } \\
\text { Ratio }\end{array}$ & FA:CBA & $\begin{array}{c}\mathrm{NaOH} \\
\text { molarity }\end{array}$ & $\begin{array}{c}\text { Compressive } \\
\text { strength } \\
\text { (MPa) }\end{array}$ & $\begin{array}{c}\text { Water } \\
\text { permeability } \\
(\mathrm{cm} / \mathrm{sec})\end{array}$ & Remark \\
\hline C1-1/0.5/1:6/10 & $5-10$ & 0.5 & $1: 6$ & 10 & 13.9 & 1.8 & \multirow{4}{*}{$\begin{array}{c}\text { Effect of } \\
\text { CBA } \\
\text { Content }\end{array}$} \\
\hline $\mathrm{C} 2-1 / 0.5 / 1: 7 / 10$ & $5-10$ & 0.5 & $1: 7$ & 10 & 13.7 & 2.1 & \\
\hline C3-1/0.5/1:8/10 & $5-10$ & 0.5 & $1: 8$ & 10 & 10.1 & 2.15 & \\
\hline C4-1/0.5/1:9/10 & $5-10$ & 0.5 & $1: 9$ & 10 & 8.7 & 2.2 & \\
\hline C6-1/0.5/1:7/10 & $5-10$ & 0.5 & $1: 7$ & 10 & 13.7 & 2.1 & \multirow{3}{*}{$\begin{array}{l}\text { Effect of } \\
\text { CBA size }\end{array}$} \\
\hline C7-2/0.5/1:7/10 & $10-14$ & 0.5 & $1: 7$ & 10 & 9.2 & 2.2 & \\
\hline C8-3/0.5/1:7/10 & $14-20$ & 0.5 & $1: 7$ & 10 & 6.4 & 2.28 & \\
\hline C9-1/0.4/1:7 & $5-10$ & 0.4 & $1: 7$ & 10 & 8.9 & 2.15 & \multirow{3}{*}{$\begin{array}{l}\text { Effect of } \\
\text { (AL/FA) }\end{array}$} \\
\hline C10-1/0.5/1:7 & $5-10$ & 0.5 & $1: 7$ & 10 & 13.7 & 2.1 & \\
\hline C11-1/0.6/1:7 & $5-10$ & 0.6 & $1: 7$ & 10 & 12.9 & 1.9 & \\
\hline C12-1/0.5/1:7/8 & $5-10$ & 0.5 & $1: 7$ & 8 & 9.1 & 1.95 & \multirow{3}{*}{$\begin{array}{c}\text { Effect of } \\
\mathrm{NaOH} \\
\text { molarity }\end{array}$} \\
\hline C13-1/0.5/1:7/10 & $5-10$ & 0.5 & $1: 7$ & 10 & 13.7 & 2.1 & \\
\hline C14-1/0.5/1:7/12 & $5-10$ & 0.5 & $1: 7$ & 12 & 12.6 & 2.14 & \\
\hline
\end{tabular}


Figure 3 contains four quarters. In the four quarters of this figure, two curves are created to indicate CBA PGC and BA PGC. The first quarter relates to the molarity of $\mathrm{NaOH}$ and the compressive strength of CBA and BA PGC mix. From this quarter, the compressive strength of CBA and BA PGC can be determined by dragging the lines from the $\mathrm{NaOH}$ molarity axis into the compressive strength axis.

In the second quarter, the compressive strength of concrete can be arbitrarily related to the AL/FA ratio of CBA and BA PGC. From the compressive strength axis, the AL/FA ratio for CBA and BA PGC can be identified.

The third quarter presents the AL/FA ratio for CBA and BA PGC that can be related to water permeability of the concrete. From the AL/FA ratio axis, the water permeability of CBA and BA PGC can be determined. The water permeability is in $\mathrm{cm} / \mathrm{sec}$ units.

The fourth quarter relates to the molarity of $\mathrm{NaOH}$ and the water permeability of CBA and BA PGC. From the $\mathrm{NaOH}$ molarity axis, the water permeability of CBA and BA of PGC can be determined. The use of this nomograph chart can be viewed in the next sub-section.

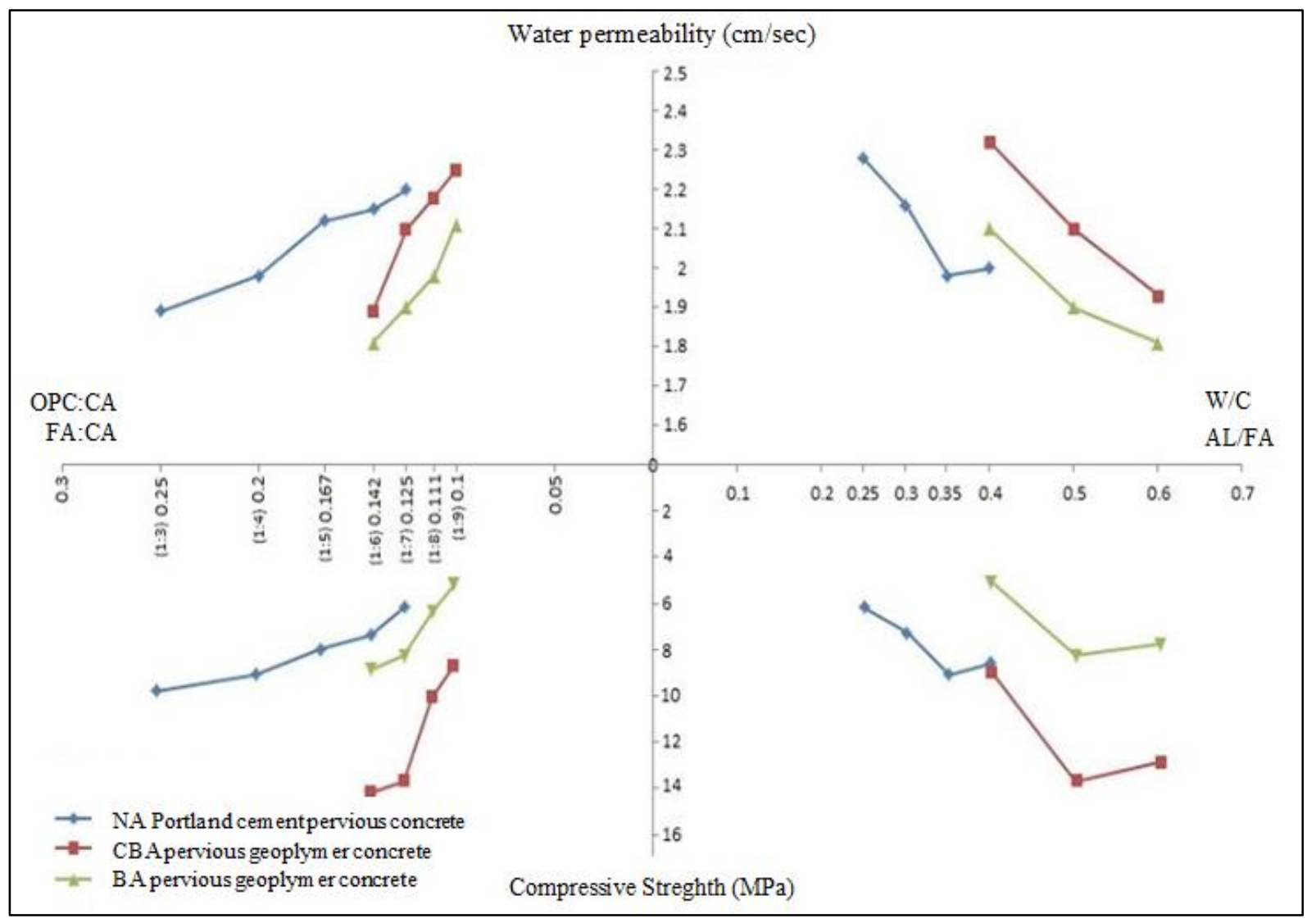

Figure 2. Nomograph chart for NA Portland cement pervious concrete, CBA and BA PGC 


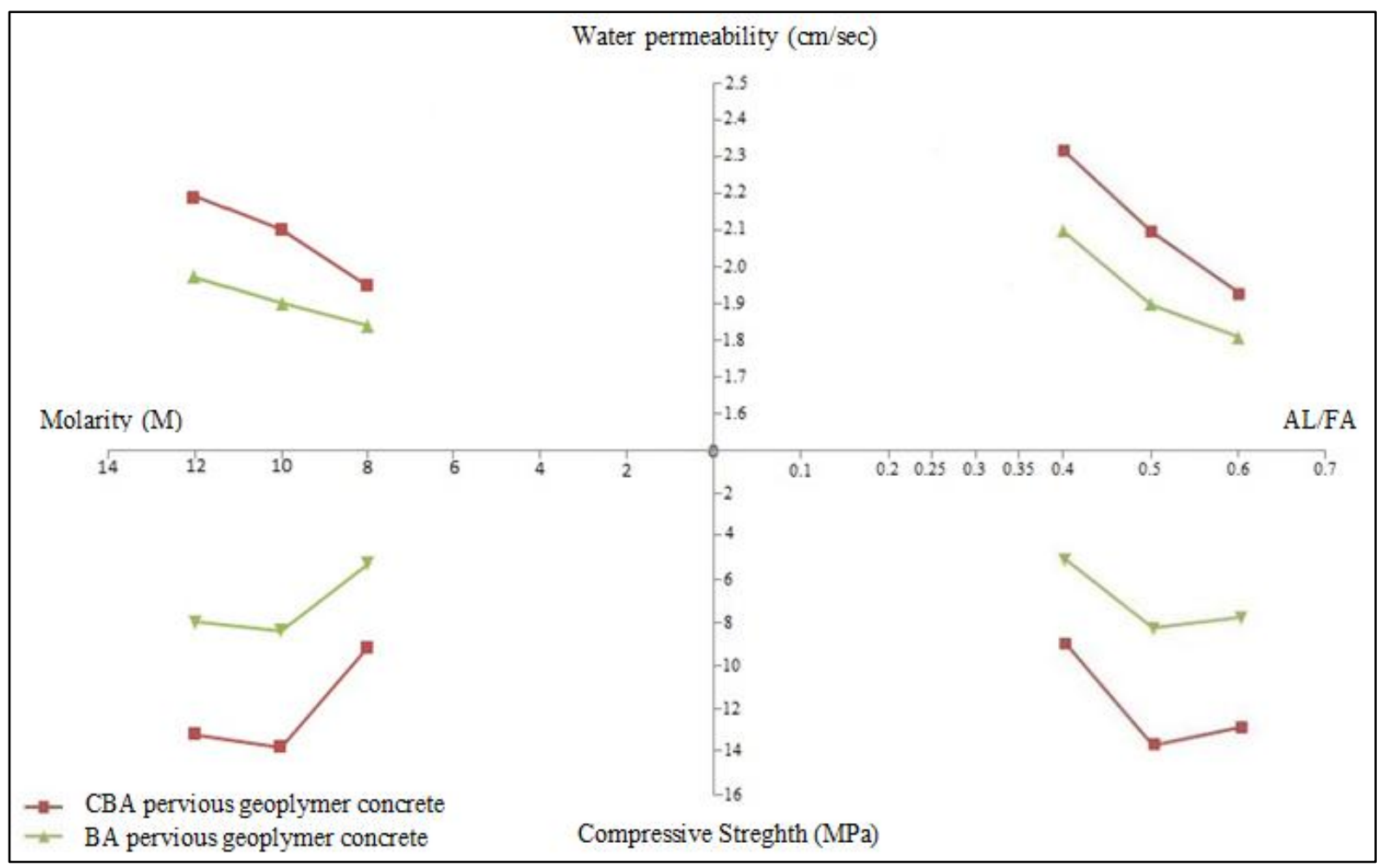

Figure 3. Nomograph chart for CBA and BA PGC

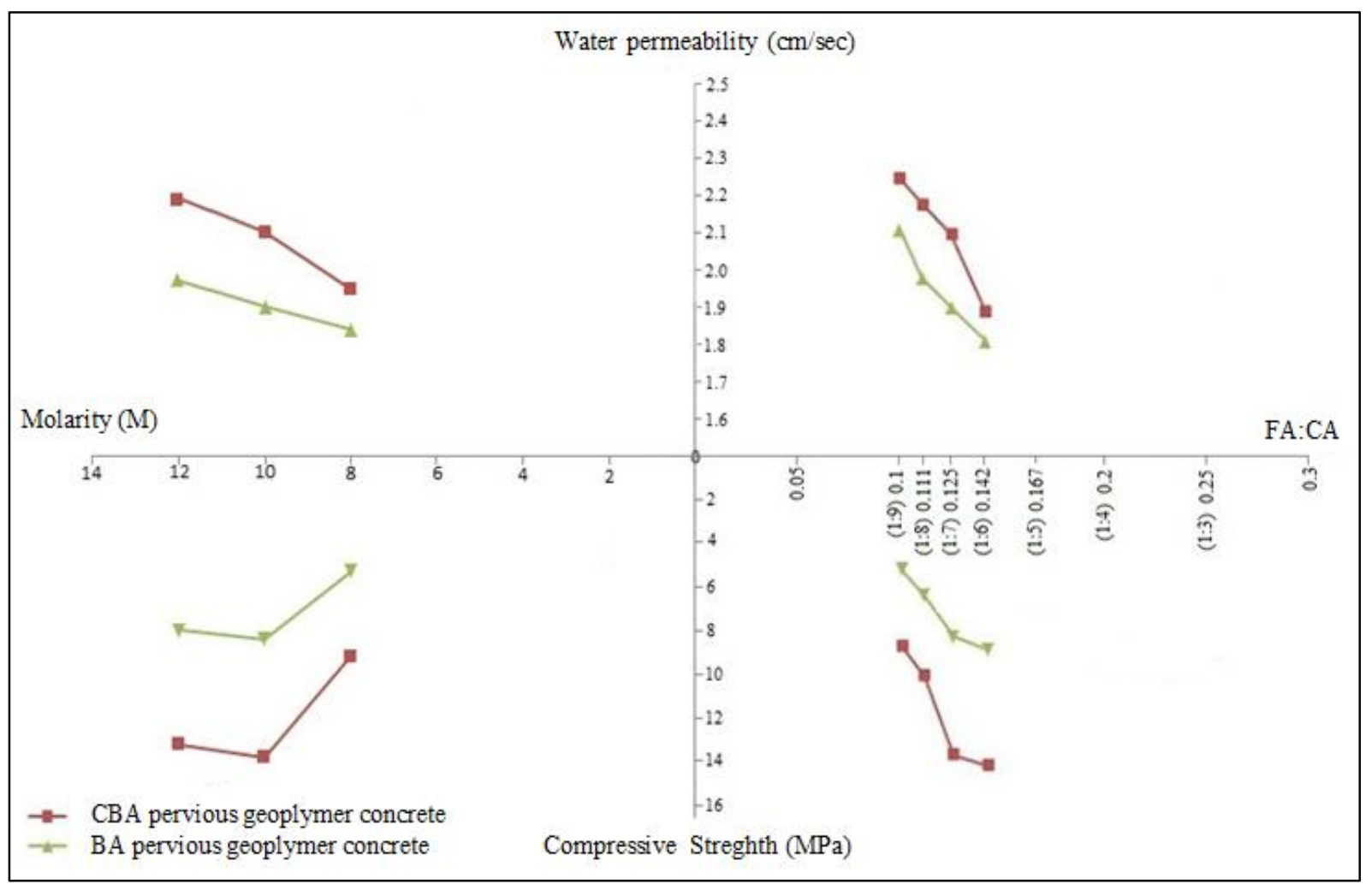

Figure 4. Application of nomograph chart NA cement pervious concrete

Figure 4 contains four quarters. In the four quarters of this figure, two curves are created that indicate the CBA PGC and BA PGC. The first quarter relates to the molarity of $\mathrm{NaOH}$ and compressive strength of $\mathrm{CBA}$ and $\mathrm{BA}$ PGC mix. In this quarter, the compressive strength of CBA and BA PGC can be determined by dragging the lines from the 
$\mathrm{NaOH}$ molarity axis into the compressive strength axis.

In the second quarter, the compressive strength of concrete can be arbitrarily related to the (FA: CBA) of CBA and (FA: BA) of BA PGC. From the (FA: CBA) and (FA: BA) axis, the compressive strength for $\mathrm{CBA}$ and $\mathrm{BA}$ PGC can be identified.

The third quarter presents the (FA: CBA) for CBA and (FA: BA) of BA PGC related to the water permeability of concrete. From the (FA: CBA) and (FA: BA) axis, the water permeability of CBA and BA PGC of concrete can be determined. The water permeability is in $\mathrm{cm} / \mathrm{sec}$ units.

The fourth quarter relates to the molarity of $\mathrm{NaOH}$ and water permeability of CBA and BA PGC. From the $\mathrm{NaOH}$ molarity axis, the water permeability of $\mathrm{CBA}$ and $\mathrm{BA}$ of PGC can be determined. The use of this nomograph chart can be viewed in the following sub-section.

\subsubsection{Examples of Applications of Nomograph Chart of Pervious Concrete}

In the nomograph chart, there is a requirement for a mix with a mean 28-day compressive strength of $7 \mathrm{MPa}$ for NA Portland cement pervious concrete; it is also important to determine the best cement-to-aggregate content (OPC: NA), w/c ratio, and expected water permeability for producing NA Portland cement pervious concrete.

From Figure 5, it was identified that 0.28 is the best w/c ratio and 1:6.5 is the best cement-to-aggregate content (OPC: NA) for NA Portland cement pervious concrete mix and the expected water permeability is $2.19 \mathrm{~cm} / \mathrm{sec}$.

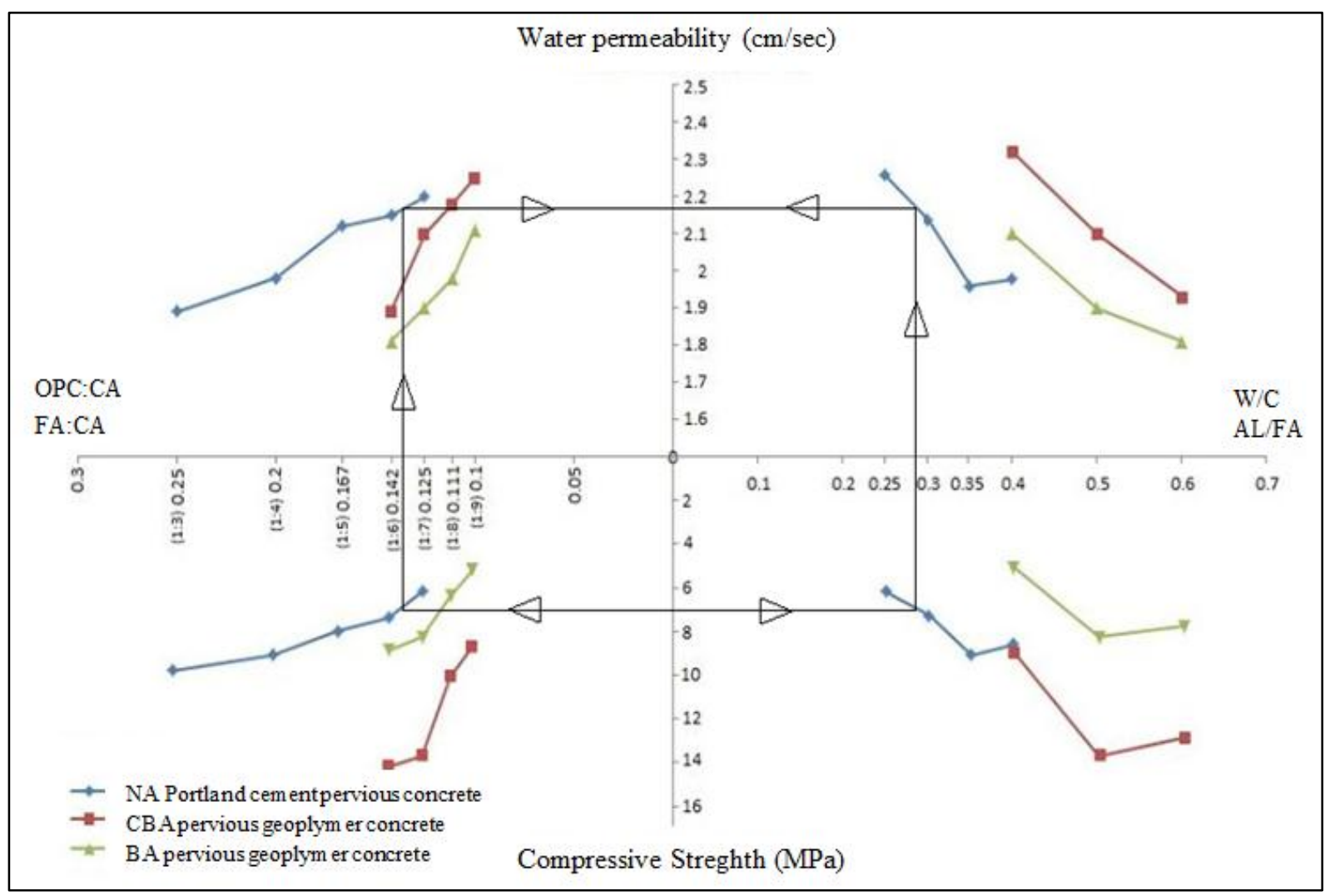

Figure 5. Application of nomograph chart NA cement pervious concrete 


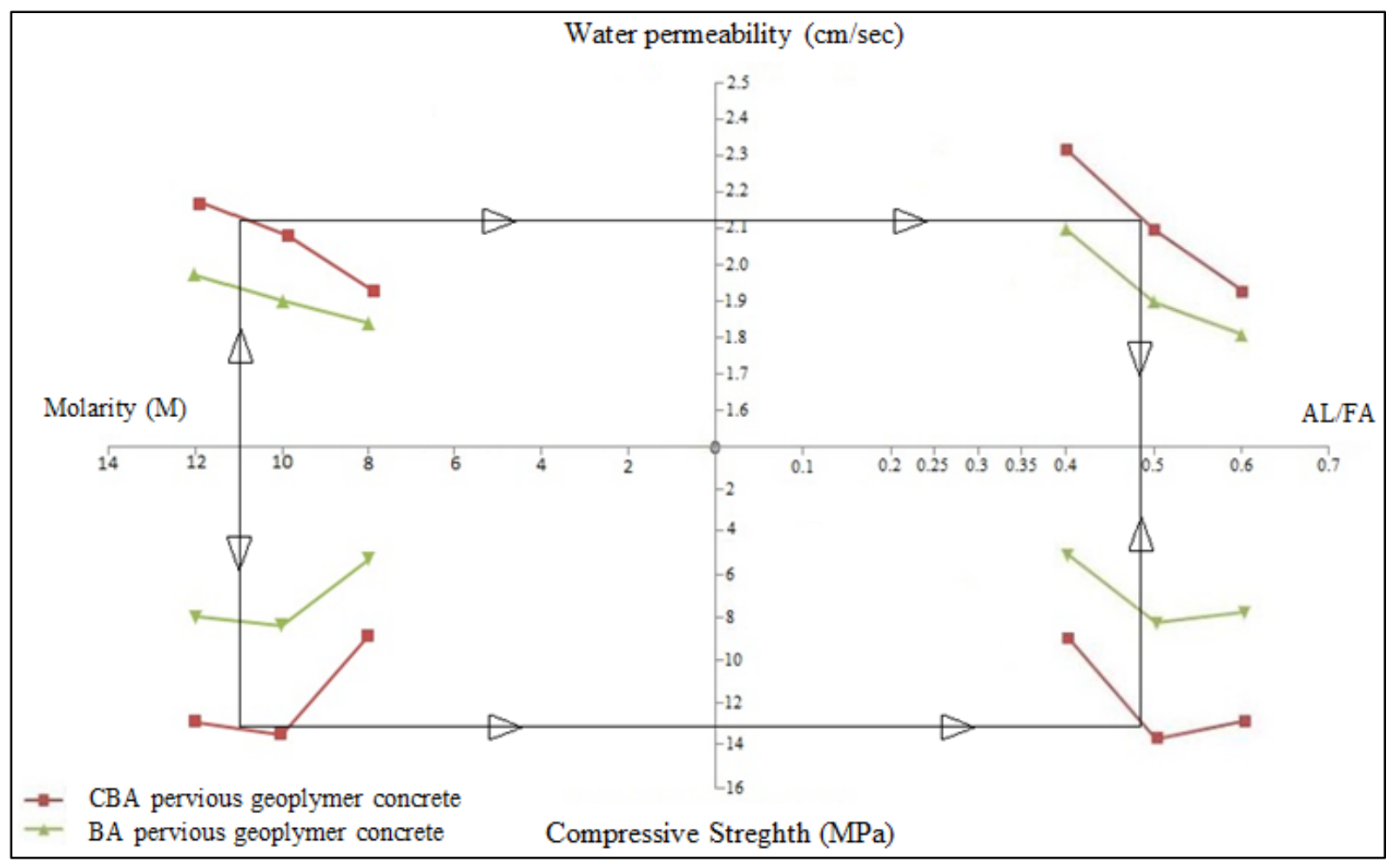

Figure 6. Application of nomograph chart CBA PGC

However, there is a requirement for a mix with an $11 \mathrm{M}$ concentration of $\mathrm{NaOH}$ for $\mathrm{CBA}$ PGC, the expected water permeability, compressive strength, and AL/FA ratio for CBA PGC. From Figure 6, it was determined that the expected compressive strength, water permeability, and AL/FA ratio for CBA PGC are $13.1 \mathrm{MPa}, 2.11 \mathrm{~cm} / \mathrm{sec}$, and 0.48 of $\mathrm{AL} / \mathrm{FA}$ ratio, respectively.

\section{Conclusions}

This research examined the development of a nomograph chart for pervious cement concrete and PGC to combine recycled biomass aggregate obtained from waste palm products with nature aggregate to form recycled coated biomass aggregate (CBA) pervious concrete. Currently, designers must perform laboratory tests on actual pervious concrete mixtures to note their structural properties for proper design. Irrespective of the design method used, new techniques for determination are required to ensure that designs are directly constructed based on the features of a particular mix design. The present research focuses on this prerequisite and offers a call-to-action to expand technology, knowledge, and testing methods concerning pervious concrete. Moreover, below are the conclusions formulated based on the results and discussions regarding the performance of NA Portland cement pervious concrete, CBA and BA PGC samples, compressive strength and water permeability for the development of nomograph charts presented in this research:

- The pervious concrete's permeability to water and compressive strength.

- Superior performance was shown by pervious concrete made of CBA and geopolymer binder in terms of permeability to water and compressive strength.

- The CBA PGC's permeability to water and compressive strength relied on the type of binder material, AL/FA ratio, CBA size, the porosity of concrete, FA: CBA ratio and $\mathrm{NaOH}$ molarity.

Reduced size of aggregate lowered the PGC's water permeability and porosity. This raised the pervious concrete's strength.

- The properties of the PGC were significantly influenced by the FA: CBA ratios. The increase in aggregate portion raised the PGC's porosity and water permeability. A reduction followed said increase in density and compressive strength of PGC.

- The compressive strength rose with a rise in the concentration of sodium hydroxide, up to $10 \mathrm{M}$. As the $\mathrm{NaOH}$ continued to rise, there was a reduction in compressive strength and a rise in the AL/FA ratio. Furthermore, the PGC's water permeability was not significantly influenced by the $\mathrm{AL} / \mathrm{FA}$ ratio, concentration of $\mathrm{NaOH}$ or the $\mathrm{Na}_{2} \mathrm{SiO}_{3} / \mathrm{NaOH}$ ratio.

- The overall outcome shows that the CBA and BA can serve as coarse aggregate with a geopolymer binder to build a pervious concrete with exceptional traits. 
- Compared to the Portland cement pervious concrete, which utilised NA, coating BA with geopolymer paste raised the compressive strength.

\section{Acknowledgments}

The authors would like to express their gratitude to Universiti Kebangsaan Malaysia for the financial support for this work through Grant No. DIP-2020-003.

\section{REFERENCES}

[1] Arafa, S. A., et al. "Properties of coated and uncoated biomass aggregates and their effects on the strength and water permeability of pervious geopolymer concrete." International Journal vol. 14, no 41. 44-51, 2018.

[2] Fung-Lung, Chang, et al. "Performance of Pervious Concrete Containing Kenaf (Hibiscus cannabinus L.) Fibres." INTI JOURNAL 1.2, 2018

[3] Arafa, Salaheddin Abdulsalam, et al. "Optimum mix for pervious geopolymer concrete (GEOCRETE) based on water permeability and compressive strength." MATEC Web of Conferences. Vol. 103. EDP Sciences, 2017.

[4] Chandrappa, Anush K., and Krishna Prapoorna Biligiri. "Pervious concrete as a sustainable pavement materialResearch findings and future prospects: A state-of-the-art review." Construction and building materials 111, 262-274, 2016

[5] Li, Jiusu, et al. "Preparation and performance evaluation of an innovative pervious concrete pavement." Construction and Building Materials 138, 479-485, 2017

[6] Richards, Daniel R., and Peter J. Edwards. "Using water management infrastructure to address both flood risk and the urban heat island." International Journal of Water Resources Development 34.4, 490-498, 2018.

[7] Liu, Hanbing, et al. "Strength Time-Varying and FreezeThaw Durability of Sustainable Pervious Concrete Pavement Material Containing Waste Fly Ash." Sustainability 11.1, 176, 2019

[8] T. Santhosh Kumar , Balaji K. V. G. D , Ch. Sandeep Reddy , K. Chitti Babu , Ch. Lakshmi Sowjanya , "Performance of $\mathrm{CO}_{2}$ Cured Sugar Cane Bagasse Ash Concrete in Marine Environment," Civil Engineering and Architecture, Vol. 8, No. 5, pp. 771 - 776, 2020. DOI: 10.13189/cea.2020.080504.

[9] Liew, Yun-Ming, Cheng-Yong Heah, and Hussin
Kamarudin. "Structure and properties of clay-based geopolymer cements: A review." Progress in Materials Science 83, 595-629, 2016

[10] Vijaya, S., et al. "Life cycle inventory of the production of crude palm oil-a gate to gate case study of 12 palm oil mills." Journal of Oil Palm Research 20. JUNE 484-494, 2008

[11] Kong, Deyu, et al. "Effect and mechanism of surface-coating pozzalanics materials around aggregate on properties and ITZ microstructure of recycled aggregate concrete." Construction and Building Materials 24.5, 701-708, 2010.

[12] Kong, Daniel LY, and Jay G. Sanjayan. "Damage behavior of geopolymer composites exposed to elevated temperatures." Cement and Concrete Composites 30.10, 986-991, 2008.

[13] Ali, M. B., Rahman Saidur, and M. S. Hossain. "A review on emission analysis in cement industries." Renewable and Sustainable Energy Reviews 15.5, 2252-2261, 2011

[14] Wallah, Steenie, and B. Vijaya Rangan. "Low-calcium fly ash-based geopolymer concrete: long-term properties." 2006.

[15] Joseph, Benny, and George Mathew. "Influence of aggregate content on the behavior of fly ash based geopolymer concrete." Scientia Iranica 19.5: 1188-1194, 2012

[16] Gronwall, T. H., Doerfler, R. W., Gluchoff, A. D., Guthery, S. B., \& Hamburg, P. H. Calculating Curves: The Mathematics, History, and Aesthetic Appeal of TH Gronwall's Nomographic Work. Docent Press 2012.

[17] Su, D., Zhou, X., Chen, Q., Jiang, Y., Yang, X., Zheng, W., ... \& Wu, S.. Prognostic nomogram for thoracic esophageal squamous cell carcinoma after radical esophagectomy. PLoS One, 10(4), e0124437, 2015

[18] Kattan, M. W., \& Marasco, J. What is a real nomogram?. In Seminars in oncology (Vol. 37, No. 1, pp. 23-26). WB Saunders, 2010

[19] American Society for Testing and Materials (ASTM) C 39/C 39M-01. Standard test method for compressive strength of cylindrical concrete specimens, 2003.

[20] ASTM International. Standard Practice for Making and Curing Concrete Test Specimens in the Laboratory. West Conshohocken: C192/C192, 2007.

[21] Tamai, M., Mizuguchi, H., Hatanaka, S., Katahira, H., Nakazawa, T., Yanagibashi, K., \& Kunieda, M. Design, construction and recent applications of porous concrete in Japan. In Proceedings of the JCI Symposium on Design, Construction, and Recent Applications of Porous Concrete, Japan Concrete Institute, April, 2004. 